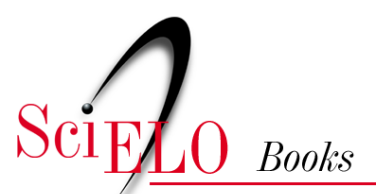

\title{
$\underline{\text { 6. Revista brasileira de epidemiologia: uma história narrada com base em }}$ $\underline{\text { seus editoriais }}$
}

\author{
José da Rocha Carvalheiro \\ Marilisa Berti de Azevedo Barros \\ Marina França Lopes
}

\section{SciELO Books / SciELO Livros / SciELO Libros}

CARVALHEIRO, J. R., BARROS, M. B. A., and LOPES, M. F. Revista brasileira de epidemiologia: uma história narrada com base em seus editoriais. In: LIMA, N. T., and SANTANA, J. P., eds. Saúde coletiva como compromisso: a trajetória da Abrasco [online]. Rio de Janeiro: Editora FIOCRUZ; Abrasco, 2006, pp. 163-186. ISBN: 978-65-5708-156-3. https://doi.org/10.7476/9786557081563.0007.

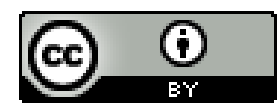

All the contents of this work, except where otherwise noted, is licensed under a Creative Commons Attribution 4.0 International license.

Todo o conteúdo deste trabalho, exceto quando houver ressalva, é publicado sob a licença Creative Commons Atribição 4.0.

Todo el contenido de esta obra, excepto donde se indique lo contrario, está bajo licencia de la licencia $\underline{\text { Creative }}$ Commons Reconocimento 4.0. 


\title{
6 REVISTA BRASILEIRA DE EPIDEMIOLOGIA: - UMA HISTÓRIA NARRADA COM BASE EM SEUS EDITORIAIS
}

\author{
José da Rocha Carvalheiro \\ Marilisa Berti de Azevedo Barros \\ Marina França Lopes
}

Traçar a história de menos de uma década de uma revista científica não é tarefa simples para ninguém. Menos ainda para quem está tão envolvido quanto os autores deste texto. Optamos por enunciar alguns itens que consideramos relevantes, redigir uma interpretação com o inevitável viés de quem viveu os momentos cruciais da elaboração da proposta da revista e, sobretudo, criou a 'carpintaria' própria de um periódico científico.

Excluindo os três primeiros itens, os demais compõem uma seleção de textos transcritos diretamente dos editoriais, intercalados com juízos críticos sintéticos, com que os responsáveis pelo periódico foram dando conta do processo que se seguiu. Após a apresentação das origens da Revista Brasileira de Epidemiologia $(R B E)$, com ênfase nas polêmicas em torno da criação de um periódico de inscrição disciplinar e do nome que deveria receber, a narrativa segue com a transcrição quase integral do editorial do primeiro número, que foi uma produção coletiva. Neste editorial é mencionada Cecília Donnangelo, que, com sua inimitável irreverência, afirmou: "somos, na Saúde Coletiva, um conjunto maior de atores do que de autores". Os demais editoriais foram em geral assinados pelo editor, porém com prévia anuência dos Editores Adjuntos. Editoriais especiais, sempre sobre temas específicos e assinados por especialistas convidados, serão também mencionados.

Dividimos o texto em seções que buscam apresentar: 1) os momentos iniciais; 2) o período de crise vivido em 2000; 3) o processo de 
recuperação e consolidação da $R B E$ de 2001 a 2004, cujo marco mais significativo foi o ingresso na base Scientific Electronic Library Online (SciELO); 4) a transcrição, na última seção, de trechos de alguns editoriais considerados especialmente relevantes por abordarem temas especiais.

\section{Momentos INICIAIS}

\section{Um conturbado prelúdio: em Itaparica o editor foi contra}

No Seminário "Estratégias para o Desenvolvimento da Epidemiologia no Brasil”, realizado em Itaparica (Bahia), em 1989, definiuse o I Plano Diretor da Epidemiologia no Brasil. Foi apresentada nessa reunião contribuição sobre as "Estratégias para divulgação da produção técnico-científica em epidemiologia", posteriormente publicada em periódico nacional (Carvalheiro, 1990). O autor da apresentação posicionouse contra a criação de um periódico brasileiro de epidemiologia. Propunha fortalecer a linha editorial da Associação Brasileira de Pós-Graduação em Saúde Coletiva (Abrasco), transformando os Estudos de Saúde Coletiva, que estavam em seu quinto volume, numa revista de Saúde Coletiva, incluindo todas as disciplinas da área, inclusive epidemiologia. Transcrevemos:

A estratégia própria da Epidemiologia Brasileira deve ser traçada em conjunto com a das demais áreas da Saúde Pública. Em vista dos resultados já conseguidos, o projeto editorial da Abrasco deve ocupar o centro do palco. Acredito que deve ser o ponto central de atuação da Abrasco: a consolidação da entidade passa pela de sua linha editorial e de seus congressos.

\section{A Comissão de Epidemiologia promove nascimento e registro civil}

Não houve consenso a respeito da proposta de Itaparica. A Comissão de Epidemiologia da Abrasco, posteriormente, decidiu ser imprescindível consolidar a área com uma publicação especializada. Aderia a uma definição operacional muito difundida na época: "uma disciplina científica tem objeto e método próprios e, ademais, um Congresso e uma Revista para discutir e difundir suas idéias". Não satisfeita, a Comissão tomou duas iniciativas 'de risco', bem a caráter para a disciplina envolvida: deu à nova revista um nome (Epidemiologia: teoria e prática) e convidou um editor científico. Ambas arriscadas: nem o nome nem o convidado eram consensuais. Afinal, tinha sido este o autor da proposta em Itaparica.

No segundo Plano Diretor, de 1995, já está formulada a proposta de "criar uma revista de Epidemiologia", considerando a "necessidade de 
ampliação da divulgação de artigos científicos e livros”. Na verdade, a estratégia de realizar as oficinas e reuniões para elaboração dos Planos Diretores da Epidemiologia (da Abrasco) foi fundamental para inibir propostas de criar uma 'Associação de Epidemiologia' desvinculada do campo da Saúde Coletiva. Essas reuniões também levaram a focalizar as questões especificamente na epidemiologia (igualmente significativas, ou não, para as outras disciplinas do campo) e sem dúvida delineando fronteiras entre as áreas. A proposta de um planejamento específico para a epidemiologia (incluída aí a criação de uma revista específica) afinava com o contexto que exigia um aprofundamento técnico-científico para garantir até mesmo a respeitabilidade e competência do campo da Saúde Coletiva. Também a experiência no mundo desenvolvido mostrava o espaço diferenciado e importante para a existência de periódicos destinados a disciplinas e subtemas específicos, processo que só fez por se aprofundar.

$\mathrm{O}$ editorial do número 1 da revista contém comentários que traduzem razoavelmente as idéias prevalecentes naquele momento. Também o projeto de criação da revista apresentado pela Abrasco ao Ministério da Saúde para obtenção de recursos traduz essas idéias. Esse projeto encontrase nos arquivos da entidade.

\section{A escolha do Conselho Editorial e dos assessores; a controvérsia a} respeito do nome e os argumentos utilizados; a votação e o 'colégio eleitoral': o empate e o desempate

O nome não agradou aos padrinhos: a celeuma criada em razão disso foi difícil de resolver. Lembrou-se que esse nome era o mesmo de um livro recentemente publicado por prestigiado professor. Este, em cortês comunicado, foi alertado formalmente sobre a coincidência dos nomes.

Os primeiros convidados para membros do Comitê Editorial receberam cartas em que constava um esboço de timbre (em português e inglês) com o nome escolhido pela Comissão. Avolumando-se o número de descontentes, foi preciso submeter a questão a um 'colégio eleitoral' arbitrariamente composto: era momento de transição entre gestões sucessivas da Abrasco, consultaram-se os membros das duas diretorias e das duas comissões de Epidemiologia (as que saíam e as que entravam!), além de todos os membros do já escolhido Conselho Editorial. Argumentos foram apresentados em favor de três possíveis denominações: "Epidemiologia: teoria e prática", "Epidemiológica" e "Revista Brasileira de Epidemiologia". Documentos produzidos na época estão conservados nos arquivos da $R B E$. Transcrevemos apenas o que constou no instrumento de coleta das opiniões (a 'cédula eleitoral'): 
EPIDEMIOLOGIA: teoria e prática. Este título condensa os dois segmentos principais de trabalho da ABRASCO: sua área acadêmica e os de saúde, além de ressaltar o vínculo entre ambos.

EPIDEMIOLÓGICA. Este título condensa o máximo de sentidos em um único termo. $\mathrm{O}$ adjetivo substantivado remete por elipse tanto ao veículo revista quanto à ciência, à pesquisa, à teoria, à prática, etc. Presta-se ainda à conotação tangencial de lógica epidemiológica que seguramente encapsula um importante elemento da "escola brasileira".

REVISTA BRASILEIRA DE EPIDEMIOLOGIA. Este título é coerente com a tradição do mercado editorial de fazer constar nos nomes dos periódicos uma indicação do país (American, British, Venezolana, Indian, etc.). A Revista vinculada à ABRASCO representa o canal natural para a divulgação de produção epidemiológica nacional.

O processo de escolha exigia maioria absoluta de votos com segundo turno entre os dois mais votados, caso não se atingisse essa maioria. Votaram 23 membros do mencionado 'colégio'. O resultado indicou empate entre "Epidemiológica" e "Revista Brasileira de Epidemiologia", com dez votos; "Epidemiologia: teoria e prática" teve apenas três votos. A votação foi aberta. Nos arquivos da revista encontram-se as cédulas assinadas pelos eleitores como testemunho desse incidente de percurso que retardou por quase um ano a edição do número inaugural. A decisão óbvia foi a de realizar novo escrutínio apenas entre os três que optaram pelo nome original. Destes, dois votaram no nome definitivo: Revista Brasileira de Epidemiologia.

Primórdios acadêmicos, técnicos e administrativos: a estrutura do peer review e a complexa proposta de dois resumos (Abstract e Extended Summary); a carpintaria da dinâmica operacional e a escolha da capa e do belo 'fôlder sanfona'

Os dois primeiros editoriais, transcritos quase na íntegra a seguir, dão conta dos arranjos em que se baseia a edição da $R B E$ e, em particular, do que tem sido sua marca mais característica, os "Debates" e a seção "Gavetas e Prateleiras":

Durante décadas os profíssionais brasileiros da área de Epidemiologia se ressentiram da ausência de uma revista especializada. Estivessem nas Universidades, Institutos de Pesquisa ou nos Serviços de Saúde. A todos sempre pareceu que um veículo próprio de divulgação conduziria, fatalmente, a uma consolidação do nosso modo de fazer epidemiologia. Intuitivamente imaginava-se que uma revista própria seria capaz de vencer a maldição que nos acompanha de sermos melhores do que faz crer a nossa produção em periódicos com crítica editorial e ampla circulação. A saudosa 
Cecília Donnangelo, cientista social de fundamental importância na saúde coletiva brasileira, traduziu essa sina com uma frase de efeito: "Somos mais atores que autores".

Em cada cabeça, por suposto, encontrava-se uma definição do que afinal tem de tão peculiar a "nossa epidemiologia". Pensemos nos precursores do século XIX e, especialmente, da passagem para o século XX. Com o surgimento da investigação experimental e "de campo" na área da saúde foi-se conformando um modelo que, ultrapassando a cabeceira do doente, deitou as profundas raizes da abordagem interdisciplinar. Foram diversos os grupos em que se deu o desenvolvimento desta nossa maneira de sermos cientistas. Estabeleceram uma competição cordial e foram capazes de dar origem a centros de pesquisa ainda hoje ativos e militantes. A maior, ou menor, proximidade da investigação de campo com o atendimento hospitalar e ambulatorial e com a chamada pesquisa biomédica básica conduziu a distintos estilos de organização da produção de conhecimento na área. Portanto, as diversas cabeças que elaboram as sentenças a respeito do que é a "nossa epidemiologia" são, como a da Hidra, são cabeças coletivas.

Assumindo essa multiplicidade, não poderíamos banalizar a proposta tanto tempo acalentada de editar uma revista da Abrasco especializada em epidemiologia. Afinal, a associação congrega todos os profissionais da área, academia e serviços. Não poderia cometer o delito de se transformar no veículo de divulgação das idéias de uma única das tendências da epidemiologia brasileira (e mundial). Deveria recolher a produção relevante na área e fazer o possível para divulgá-la amplamente. Sem qualquer patrulhamento ideológico ou epistemológico. Baseando sua política editorial na qualidade e na relevância das contribuições e no julgamento pelos pares. Com rigorosa crítica editorial.

Para atender aos anseios de ampla divulgação no exterior, foram tomadas medidas de dupla natureza. Primeiro, quanto ao idioma. Reconhecer a realidade do inglês como a língua franca contemporânea não representa necessariamente submissão a nenhum tipo de colonialismo cultural. Até porque houve o reconhecimento, também, da realidade da integração econômica, política e cultural da América Latina. Não é por acaso que já se fala, fora do continente, numa epidemiologia latino-americana. Decidiu-se aceitar artigos e contribuições nos três idiomas: português, espanhol e inglês com um Resumo mais extenso (Extended Summary) em inglês, sempre que o texto principal for escrito num dos outros dois idiomas. A segunda medida dirigiu-se ao âmbito da divulgação e da busca ativa de autores. Desencadeouse uma ampla campanha em diversos países, especialmente por intermédio de veículos internacionais. Não há contradição, se quisermos ser lidos lá fora precisamos abrir nossos veículos de debate científico às contribuições do exterior. Os modernos meios de comunicação de idéias, que já invadiram o âmbito da ciência, estão aí para serem usados. 
Para que essas idéias se concretizassem foi uma árdua jornada. Reuniões semanais entre os editores indicados, a Comissão de Epidemiologia, a Secretaria Executiva e a própria Diretoria da Abrasco. Durou mais de um ano esse processo complexo. A escolha definitiva do nome da revista foi mais tumultuada do que se esperava. Superou, na polêmica, a discussão sobre a composição do Conselho de Editores: editor científico, editores adjuntos e associados, grupo de assessores. Por fim, esse ideário veio à luz através de um folheto de divulgação e propaganda que registra um momento importante da epidemiologia brasileira.

Ao mesmo tempo que se davam os passos decisivos na escolha do eixo da revista, começou o trabalho de garimpo de contribuições. Desde logo decidiu-se pela não edição de um "número zero" composto exclusivamente por artigos encomendados. Encomendar significa, quase certamente, a obrigação de publicar. Ou, então, não é encomenda. Preferiu-se incentivar os autores potenciais a encaminharem suas contribuições, sem configurar compromisso com a publicação automática. Este é um processo mais seguro, porém extremamente demorado. Um trabalho encaminhado não leva menos que seis a oito meses para vencer todas as etapas. Pelo menos nesta fase inicial de estabelecimento das rotinas de trabalho e da "carpintaria" da revista. Contamos com o apoio contínuo de diversas pessoas e instituições das quais devem ser mencionadas: em primeiro lugar, a Secretária da revista, Maria Luiza Ernandez (Malu), que emprestou sua dedicação e experiência à tarefa de tornar operacionais as idéias que iam sendo formuladas, em particular pelo papel decisivo na composição da equipe técnica de revisão, tradução e normalização; a Faculdade de Saúde Pública da USP, em cujas dependências nos instalamos, com todas as facilidades oferecidas por sua Diretoria; além dos organismos próprios da instituidora, Abrasco e do patrocinador Cenepi, do Ministério da Saúde.

O ritmo de recepção das contribuições, inicialmente lento, foi-se acelerando com o tempo. Embora o lançamento do primeiro número tardasse mais do que imaginávamos, acreditamos que a divulgação foi eficaz e responsável pelo fluxo contínuo dos trabalhos. Os próprios relatores, recrutados por indicação dos Editores Associados, devem ter servido como amplificadores da notícia. Afinal, ninguém melhor do que eles para anunciar que a revista vivia, ainda que não tivesse visto a luz do dia. Foi um parto demorado, mas eutócico. Pelo menos no que diz respeito ao fiel cumprimento das regras do jogo, previamente enunciadas. Os autores que tiveram trabalhos "transitados em julgado" foram os primeiros a saber: seriam publicados no número inaugural, após terem circulado, sob anonimato, pelo sistema de julgamento pelos pares.

Este número inaugural da Revista traduz o longo percurso descrito acima. Compõe-se de trabalhos que expressam uma diversidade temática com que certamente editores, autores e leitores irão sempre conviver. É auspicioso 
que, sem que tenha havido nenhum esforço especial, já no primeiro número apareçam trabalhos em dois idiomas oficiais da Revista. O Corpo de Editores aguarda, com fundadas esperanças, que o conjunto dos profissionais da área encaminhem contribuições que se enquadrem na nossa proposta editorial. Sobretudo, que encaminhem sugestões, críticas e comentários relacionados com o projeto de implantação da Revista, que se pretende coletivo. (Revista Brasileira de Epidemiologia, 1(1), abr.1998)

Este segundo número da Revista Brasileira de Epidemiologia apresenta duas novidades que se incorporam a nossa linha editorial, como já havia sido anunciado anteriormente. Uma, o primeiro Artigo Especial, modalidade com que os leitores passarão a conviver daqui por diante. Serão sempre textos encomendados a especialistas consagrados em nosso campo temático. Para inaugurar esta seção, seria difícil encontrar Autor mais consagrado, verdadeira unanimidade internacional como um dos maiores epidemiologistas do século, Sir Richard Doll. O texto escolhido é inédito, tendo sido apresentado pelo Autor como Conferência no Congresso de Epidemiologia da Abrasco, realizado no Rio de Janeiro (EpiRio 98).

A segunda novidade é a inauguração de uma Seção de Debates. Esta será uma seção permanente da Revista, embora nem sempre formalizada na modalidade com que se apresenta neste número. A idéia é manter acesa a polêmica, o debate, a controvérsia sobre temas relevantes em nosso campo de atuação. Daremos espaço ao debate de idéias em qualquer dos terrenos: teórico, prático, metodológico, opinião. Por sua essência, será a seção de Correspondência aquela em que os leitores poderão participar espontaneamente tornando-a dinâmica e conduzindo as discussões para o terreno de escolha do público leitor. Eventualmente, o debate poderá ser induzido juntando cartas espontâneas e críticas encomendadas, antes da resposta do autor original. Será uma espécie de Consenso e Dissenso, habitual em algumas revistas da área.

Um formato mais convencional inicia o processo por um artigo encomendado, seguem-se críticas também encomendadas e finaliza com a resposta do primeiro autor. Neste número damos início a este tipo de debate com um artigo Por uma epidemiologia da saúde coletiva e comentários de dois membros do Comitê Editorial da Revista.

Outro tema para debate mais formal já foi escolhido pelo Comitê Editorial. Trata-se de ingressar numa polêmica que, no momento, figura com destaque na maioria dos periódicos científicos de circulação mundial. Existem múltiplas éticas na pesquisa científica que envolve seres humanos? Haverá uma ética para as investigações realizadas nos países subdesenvolvidos, mais branda que a dos países industrializados? A ética das investigações de "mundo real", envolvendo milhares de pessoas, na reta final dos testes de eficácia (fase III) de medicamentos e vacinas, é diferente da ética dos ensaios 
em pequena escala (fase pré-clínica e fases clínicas I e II)? Para introduzir este tema na literatura científica epidemiológica no Brasil, encaminhando uma espécie de visão terceiro-mundista nesta polêmica mundial, escolhemos uma das questões mais candentes da atualidade: a Controvérsia da Vacina anti-HIV/aids. Para coordenar o Debate foi convidado Dirceu Bartolomeu Greco, da UFMG, que tem representado o Brasil em diversos encontros internacionais sobre o tema promovidos pela UNAIDS (OMS). Os debatedores serão convidados pelo Editor Especial para encaminhar contribuições de extensões variáveis. Geralmente, haverá um ou mais artigos introdutórios, seguidos no mesmo número ou em números sucessivos da Revista por contribuições de menor extensão, encomendadas ou espontâneas. Nesta modalidade também serão aceitas sugestões dos leitores para novos temas e debatedores.

Uma alternativa, mais usada em jornais diários e que tentaremos adaptar a uma revista periódica de Epidemiologia, é a de simplesmente enunciarmos temas que podem ser debatidos de uma maneira menos formal, num momento inicial, para se transformarem num debate mais formal, na seqüência. As contribuições, neste caso, necessariamente limitadas em sua extensão, por exemplo a uma página, serão selecionadas por um dos Editores da Revista. Também, como no caso anterior, serão aceitas sugestões.

Outra modalidade será constituída por Mesas-Redondas, reais ou virtuais, geralmente encomendadas pelos Editores. Algumas poderão ser as que se programarem para Congressos da área, mas não somente; a Redação da Revista poderá ser o palco da Mesa-Redonda, com ou sem público. Esperamse sugestões.

Entrevistas especiais e Reportagens, geralmente conduzidas pelo corpo de Editores, também poderão ser indutoras de debate. Sugestões também aqui são bem-vindas, sendo natural que os Congressos da área, realizados no Brasil ou no exterior, sejam momentos privilegiados para a realização destas atividades.

A seção Gavetas e Prateleiras, que será inaugurada no próximo número, também deverá ser uma fonte inesgotável de temas para debate. Por sua essência, estará aberta a indicações de textos.

Procuramos indicar os formatos das seções de Debates mais comuns em revistas da mesma natureza desta Revista Brasileira de Epidemiologia. Evidentemente, esperam-se sugestões dos leitores que superem nossa limitada criatividade. Quem sabe não poderemos ter alguma idéia inusitada provinda dos leitores e que acabe por ser a marca registrada dos nossos debates? $\mathrm{O}$ conteúdo principal deste número é resultado do processo editorial convencional, comum a todos os periódicos científicos. Conduzido pelos Editores, tem como protagonistas os Autores, os Editores Associados e os pareceristas ad hoc recrutados na comunidade científica da área. Este processo 
de revisão por pares (peer review) caminha sempre com suas próprias pernas. Mantidas as regras enunciadas em nosso número inaugural, os artigos irão sendo publicados à medida que completem o longo percurso de interação entre pareceristas e autores. (Revista Brasileira de Epidemiologia, 1(2), ago.1998)

Ainda no primeiro ano é publicada a primeira "Prateleira": Winslow e Gunnar Myrdal discutem em Genebra o "Valor econômico da saúde" dos brasileiros Ribeiro, Ferreira \& Braga:

Com este número completamos o primeiro ano da Revista Brasileira de Epidemiologia. Tem sido uma árdua batalha que estamos nos esforçando por vencer com auxílio dos leitores, colaboradores e, em especial, de nossos pareceristas ad hoc. Incluímos nele um Artigo Especial, um primeiro trabalho da seção Gavetas e Prateleiras, além de seis Artigos Originais.

Inauguramos neste número a seção Gavetas e Prateleiras, com a finalidade de resgatar textos importantes que tenham marcado época pelo seu significado no campo teórico, metodológico ou mesmo pela riqueza de um relato factual. Poderão ser inéditos (as gavetas) embora divulgados informalmente, o que é uma tradição em nossa área. Preferivelmente serão publicações “clássicas” de grande repercussão, ou mesmo precursores que tenham passado (quase) despercebidos, sempre com grande potencial de gerar polêmica e/ou controvérsia que alimente a seção correspondente da Revista (as prateleiras). Esperam-se indicações dos leitores para textos nesta seção.

A primeira contribuição para esta seção é curiosa. Como se verá na apresentação do Editor convidado, José Ruben de Alcântara Bonfim, o documento escolhido como inaugural somente teve uma edição extremamente limitada, quase um mimeografado. Embora uma publicação da extinta Fundação SESP, do Ministério da Saúde, não se encontra em nenhum registro oficial. Não consta também de nenhum dos registros de publicações dos autores. É, portanto, uma espécie de híbrido entre uma gaveta e uma prateleira. Destaco dois aspectos relevantes. Um, relacionado com a verdadeira obra de arqueologia que o Editor especial, José Ruben, realizou; outro, com a obra em si. Acompanhar o trabalho do Editor especial foi fascinante: com a estreita colaboração do Dr. José Esparza, da UNAIDS, em Genebra, foi possível ter acesso às atas da Assembléia Mundial de Saúde em que os brasileiros "Maneco" Ferreira e Ernani Braga apresentaram o Economic value of health. Daí a ter um levantamento completo da Bibliografia do final da obra foi uma distância enorme, coberta pelo Editor especial com pertinácia. Descobrir quem foi o autor principal, Paulo de Assis Ribeiro, e seu papel de relevo intelectual no IBGE, um verdadeiro achado. Perceber que a seção da Assembléia Mundial de Saúde em que a questão da economia em saúde foi introduzida teve a presença de dois vultos que marcaram este século: o sanitarista Winslow e o economista Myrdal. Enfim, descobrir no autógrafo que um dos autores (Manoel Ferreira) 
escreveu, dedicado ao Professor Pedreira de Freitas, a cuja Biblioteca particular pertenceu o exemplar resgatado, sua curiosa opinião pessoal sobre sua obra: "se o seu problema é insônia, eis o remédio". Quanto ao trabalho em si, é instigante a maneira como há quase cinqüenta anos, no limiar de um novo período, após a tragédia da Segunda Guerra Mundial, já havia uma preocupação de medir a saúde e a doença do ponto de vista econômico. Numa visão produtivista, baseada nos gastos diretos e indiretos com a manutenção da saúde e as perdas devidas à morte prematura e à doença. Passados quarenta anos, em 1993, o Banco Mundial lança suas idéias de privatização das ações de saúde mais complexas, de uma cesta básica de ações mais simples. E introduz uma medida única para a carga da doença, com pesado componente econométrico. No intervalo, diversas outras tentativas foram feitas. Ressalte-se, ao menos, a do National Center for Health Statistics, dos EUA, que aproveitou seus inquéritos domiciliares de morbidade referida para compor um indicador sintético de tempo de vida perdido devido à doença e à morte, além de outros possíveis indicadores de anos de vida perdidos prematuramente. $\mathrm{O}$ trabalho que ora divulgamos é um importante precursor. Esperamos que tenha o mérito de iniciar na Revista um importante debate sobre este tema tão atual. Fizemos um esforço especial para atualizar as fórmulas do texto, desenhadas à mão no original. Não podemos terminar sem antes citar do texto pelo menos uma das observações impregnadas de intenso humor, tão próprias de nossos queridos e saudosos Ferreira e Braga: Após a abolição da escravatura, a idéia de atribuir um valor financeiro ao homem foi quase abandonada por algum tempo. No sistema antigo, pelo menos, apenas uma pequena parcela da população tinha um valor em dinheiro e o homem livre valia menos que o escravo.

Passado tanto tempo, o tema volta a nos perseguir. (Revista Brasileira de Epidemiologia, 1(3), dez.1998)

\section{A CRISE INICIAL}

$O$ difícil começo: os critérios Capes de classificar revistas com influência na avaliação de desempenho das pós-graduações; a crise de fluxo e os 'artificios' empregados: um número só num volume que deveria ter três; o III Plano Diretor para o Desenvolvimento da Epidemiologia no Brasil

Os editoriais do segundo ano misturam esperança, resignação e sobretudo decepção. As dificuldades momentâneas fizeram com que se produzissem números temáticos, sem renunciar à qualidade do texto e à relevância dos temas. Em 2000, no ponto mais crítico da crise, chegamos ao extremo de publicar os três números num único exemplar da $R B E$. O editorial, lamuriento, apelava à comunidade de epidemiologia para um compromisso com a sobrevivência da publicação. Traz implícita uma crítica 
à introdução dos critérios da Coordenação de Aperfeiçoamento de Pessoal de Nível Superior (Capes) de julgar os programas de pós-graduação, com reflexo imediato na viabilidade das revistas novas. Ponto importante foi divulgar o III Plano Diretor de Desenvolvimento da Epidemiologia.

Este exemplar incorpora os três números do volume 3 da Revista Brasileira de Epidemiologia, correspondente ao ano de 2000. Trata-se de uma maneira legítima de colocar em dia a circulação da Revista. Porém, exige uma reflexão a respeito por parte dos principais interessados, os epidemiologistas das instituições acadêmicas, de pesquisa e de serviços, que participam do processo, simultaneamente, como produtores e "consumidores" dos novos conhecimentos. A Revista pertence a eles, mais do que ao corpo de editores, à Comissão de Epidemiologia e à própria Abrasco. Sem a ativa participação de autores da área, enviando suas contribuições com prioridade para a nossa Revista, esta não poderá sobreviver. Já foi dito, no Editorial do número inaugural, citando Cecília Donnangelo, que nossa área tem "mais atores que autores". Essa afirmação deve ser contextualizada, na medida em que representava um reconhecimento de que a maneira brasileira de fazer epidemiologia tinha várias moradas, das quais a publicação em revistas especializadas não era a mais freqüentada. Este momento está ultrapassado. Por mais que nos atinja em cheio a classificação de periódicos introduzida recentemente no cenário da pós-graduação no Brasil, é uma realidade com a qual devemos conviver. Ou lutar para transformar. Os programas são avaliados, em grande parte, através do número de trabalhos publicados em "revistas de impacto". É inevitável que os que batalham para figurar entre os melhores em cada área, o que é legítimo, direcionem sua produção apenas para aqueles veículos que podem contribuir para uma boa avaliação. Estabeleceu-se um círculo vicioso que, se não for rompido, inviabiliza o surgimento de novos periódicos com padrão de exigência e julgamento por pares igual ao dos veículos já consolidados em cada área do conhecimento.

A Revista Brasileira de Epidemiologia, apenas ao completar dois volumes, foi capaz de iniciar o processo de indexação, com limitado sucesso por enquanto. Porém com boas perspectivas, em vista do reconhecimento do elevado padrão de julgamento científico ao qual não podemos renunciar. Estão em curso apenas algumas medidas puramente editoriais, como a edição de números temáticos e de revisão, compostos por trabalhos encomendados, mas também submetidos à apreciação de especialistas designados ad hoc. $\mathrm{E}$ outras, meramente técnicas de editoração como a redefinição da maneira de divulgar o sumário estendido, que atualmente é exigido além do usual abstract. Uma das idéias é a de suprimir o sumário estendido da edição em papel, remetendo ao site da Abrasco para a divulgação do mesmo, apenas daqueles artigos, em português ou em espanhol, dos quais os autores tenham providenciado a elaboração. Parece uma questão de menor importância, mas tem sido um constante entrave editorial a maneira pouco clara como os 
autores têm interpretado a diferença entre essas maneiras de registro simplificado de seus trabalhos.

Neste número estamos divulgando o III Plano Diretor para o Desenvolvimento da Epidemiologia no Brasil, 2000 a 2004, elaborado pela Comissão de Epidemiologia da Abrasco, através de um complexo processo no qual figuraram praticamente todos os segmentos de relevância na área. Sendo a terceira versão de um Plano que já demonstrou sua importância nas anteriores, resta-nos esperar que sirva para orientar o desenvolvimento da área na pesquisa, no ensino em todos os níveis, nos serviços, na formulação de políticas e na avaliação de saúde. (Revista Brasileira de Epidemiologia, 3(1-3), abr.-dez.2000)

\section{A Recuperação}

\section{A entrada no Lilacs e a recuperação}

A tão esperada fase de consolidação inicia-se em 2001, com a inclusão na base Literatura Latino-Americana e do Caribe em Ciências da Saúde (Lilacs) de revistas científicas. Essa maior visibilidade fez crescer o fluxo dos trabalhos encaminhados. Simplificação editorial importante consistiu na eliminação do Extended Summary, que vinha sendo motivo de conturbação entre revisores e autores. Apesar da recuperação, o número inteiro foi dedicado a um único tema.

Com este número iniciamos a publicação do volume 4 da Revista Brasileira de Epidemiologia, após a conquista importante de sua inclusão na base LILACS de revistas científicas. O fluxo de trabalhos enviados pelos autores faz-nos crer que em futuro próximo estaremos em fase com o período de referência, editando os dois números restantes deste volume. No próximo número iniciaremos a nova sistemática de publicação dos Sumários Estendidos em meio eletrônico, mantendo na revista impressa apenas o Abstract. (Revista Brasileira de Epidemiologia, 4(1), abr.2001)

Novos campos temáticos vão se incorporando, em particular da área de odontologia. $\mathrm{O}$ editorial alerta para perigosa concentração na origem dos trabalhos.

Neste número são apresentados resultados de estudos em campos temáticos de grande diversidade. A área de estomatologia e odontologia é contemplada em dois. Num deles comparam-se resultados de três levantamentos epidemiológicos numa mesma população, empregando diferentes padronizações dos índices de cárie dentária para dentes permanentes e decíduos. O outro é também relacionado com a comparação de sistemas de classificação de entidades mórbidas. Contrasta, para o atendimento de 
traumatismos buco- maxilo- faciais e emergências dentais, a CID-10 com uma Classificação Internacional de Doenças em Estomatologia e Odontologia (CID-OE). (Revista Brasileira de Epidemiologia, 4(2), ago.2001)

A lenta, mas segura, recuperação: para garantir a entrada no SciELO, a RBE passa a ser trimestral

$\mathrm{Na}$ busca do reconhecimento abre-se a perspectiva de números especiais com temas sugeridos pela comunidade científica. Aprofunda-se, no entanto, a predominância dos trabalhos encaminhados pelo fluxo contínuo. Começa a delinear-se a característica dos artigos e seus autores. Finalmente entramos em fase: a publicação aparece impressa no 'mês de face'. Agradecimentos a quem mais os merece: a equipe de suporte administrativo e técnico. Ainda mais: torna-se trimestral, concretizando a recuperação.

Este número da Revista Brasileira de Epidemiologia introduz uma importante mudança. É o primeiro de uma nova prática editorial aprovada pela Comissão de Epidemiologia da ABRASCO: passaremos a ter uma periodicidade trimestral, com quatro números por volume. Além disso, as linhas temáticas passarão a ser incluídas nas edições normais, numa seção especial que terá continuidade em números sucessivos até completar a proposta original quando se decidiu aceitar o tema. Esta nova prática não altera a política editorial da Revista, que permanece rigorosamente a mesma. Todos os artigos publicados passam por uma revisão por pares (peer review), indicados por Editores Associados, sendo estes os responsáveis pela proposta definitiva quanto à aceitação do artigo. O Editor Científico e os Editores Adjuntos zelam pelo fiel cumprimento desta política editorial que pertence à comunidade científica da área e foi aprovada pela Comissão de Epidemiologia quando a Revista foi criada. Em raras ocasiões, nestes quase seis anos de existência da Revista, o Editor e os Adjuntos tiveram que intervir numa espécie de "voto de Minerva". (Revista Brasileira de Epidemiologia, 6(2), jun.2003)

No ano de 2003 atingimos a regularidade:

Ressaltamos o Editorial Especial sobre a Ética em Pesquisa envolvendo seres humanos, de autoria do Professor Dirceu Bartolomeu Greco, da UFMG. O Prof. Greco esteve, em setembro, na reunião da Associação Médica Mundial realizada no próprio berço da Declaração de Helsinque. Foi investido da autoridade conferida em reunião realizada em agosto, no Conselho Federal de Medicina, para apresentar proposta em nome do Brasil. Contrapunha-se à tendência de "abrandar" a Declaração, no que diz respeito ao acesso a cuidados médicos para voluntários em ensaios clínicos. Estiveram na reunião de Brasília, além do CFM, a Sociedade Brasileira de Bioética, CONEP do 
Conselho Nacional de Saúde, a Coordenação Nacional de DST/aids e seu comitê de Vacinas anti-HIV, a Associação Médica Brasileira e o Departamento de Ciência e Tecnologia (DECIT/MS). AABRASCO esteve presente através do Editor da RBE. A posição levada a Hensinque pelo Prof. Greco foi vitoriosa, contribuindo para evitar o pretendido "abrandamento" e remetendo o assunto para uma análise de um comitê internacional de cinco naçõesmembro, entre elas o Brasil, representado pelo Prof. Greco. Além do Editorial Especial sobre o tema, transcrevemos o comunicado oficial da Associação Médica Mundial. Assunto candente como esse exige reflexão profunda. Esperamos estar dando início a um debate franco através das páginas da RBE. (Revista Brasileira de Epidemiologia, 6(4), dez.2003)

Finalmente entramos no SciELO por termos consolidado as características essenciais. Consolidamos também a seção "Debates":

Este número da Revista Brasileira de Epidemiologia pode vir a se tornar um marco na sua história. É o primeiro editado após ter sido incluída na Plataforma SciELO. Este fato faz com que os trabalhos aqui publicados tenham maior divulgação, ao menos no continente americano, em particular na América Latina.

A razão principal pela qual fomos contemplados com essa inclusão no SciELO está muito viva neste número. Os artigos publicados consolidam o que vem ocorrendo neste ano, desde que nos colocamos "em dia" e passamos a publicar os números no mesmo mês de face. São artigos originais que passaram pelo convencional peer review conduzido por um Editor Associado. Como já vem sendo exaustivamente assinalado pelos editores, a RBE vai adquirindo sua feição: nenhum dos trabalhos é de autoria individual, a média de autores é de 3, 2; há grande variedade temática, de origem geográfica e vínculos institucionais.

Numa Seção de Opinião, que cada vez mais pretendemos permanente, damos a palavra a um "médico general" espanhol, Juan Gérvas. A leitura de seu texto é auto-explicativa da razão pela qual preferimos manter sua identificação em espanhol. Exerce a medicina numa localidade próxima de Madrid (Canencia de la Serra), faz parte de um grupo que trabalha em atenção primária, com interesse em ensino e pesquisa na Espanha (CESCA). Também é Professor Visitante da Escola de Saúde Pública de Johns Hopkins (Baltimore). O texto publicado é a sua contribuição num Seminário Internacional sobre Cuidados Básicos em Saúde, realizado em Brasília, em dezembro de 2003, organizado pela OMS e pela UNICEF para celebrar os 25 anos da Declaração de Alma Ata. Nessa reunião falaram autoridades do porte de Halfdam Mahler, Diretor Geral da OMS em 1978, o principal responsável pela realização da Reunião de Alma Ata, o atual diretor Lee Jong-Wook e a Diretora da OPAS, Mirta Roses, além do Ministro Humberto Costa. Chamaram a atenção a fala da representante africana e, especialmente, a deste médico europeu que contextualiza a atualidade dos cuidados primários de saúde no 
continente europeu. Refere a evidência obtida por "estudo epidemiológico com desenho ecológico" ao associar melhores condições de saúde à presença de uma Atenção Primária em Saúde "forte". Ao comentar "prevenção quaternária", faz uma sagaz comparação com o método epidemiológico: propõe combinar de forma construtiva o valor preditivo negativo da ação do generalista com o valor preditivo positivo daquela do especialista. Essa contribuição, que oferecemos a nossos leitores, nos induz a afirmar que teríamos muito a ganhar estabelecendo laços mais estreitos com este grupo espanhol. Quando menos, para aprender o que estão chamando de APS "forte" e seu conceito de "quaternária". (Revista Brasileira de Epidemiologia, 7(3), set.2004)

Consolidamos a presença no SciELO:

Este número encerra o volume 7 da Revista Brasileira de Epidemiologia, no mês de face da capa, dezembro de 2004. Neste ano, tivemos o reconhecimento do Comitê do SciELO e fomos admitidos nessa base de dados. Isto nos desafia a seguir no mesmo ritmo, o que não é missão do Corpo de Editores mas da comunidade científica da área. A ela e só a ela pertence esse mérito. Destacamos, ainda desta vez, o trabalho do nosso corpo de Editores Associados e do apoio da Secretaria Executiva e dos responsáveis pela revisão e normalização dos idiomas português e inglês, da editoração e da impressão. Foram os responsáveis diretos pela nossa qualidade editorial, que nos garantiu a aceitação pela base SciELO. Conservar essa qualidade deve se associar ao rigor do julgamento por pares para seguirmos publicando a "boa produção epidemiológica”, nossa proposta maior. No próximo ano, consolidada nossa posição no SciELO, vamos em busca de novas bases que ampliem ainda mais nossa circulação no mundo científico nacional e internacional. (Revista Brasileira de Epidemiologia, 7(4), dez.2004)

O que foi publicado: número de artigos, procedência geográfica, número de autores por artigo, a classificação por gênero (predominância feminina)

Nesse período de quase dez anos publicamos quatro suplementos especiais. Dois deles constituíram o Livro de Resumos do V Congresso Brasileiro de Epidemiologia (EPI 2002), realizado em março de $2002 \mathrm{em}$ Curitiba (PR), e do I Simpósio Brasileiro de Vigilância Sanitária (Simbravisa), realizado em dezembro de 2002, em São Paulo (SP). Um terceiro Livro de Resumos, do VI Congresso Brasileiro de Epidemiologia, realizado em junho de 2004, em Recife (PE), apareceu apenas em meio eletrônico (CD-ROM) em vista do extraordinário número de trabalhos apresentados, o que o tornaria difícil de manusear em volume impresso. Outro suplemento especial apareceu em novembro de 2002, com algumas apresentações consideradas particularmente expressivas do Congresso de Curitiba do mesmo ano. O 
IV Plano Diretor para o Desenvolvimento da Epidemiologia no Brasil 20052009 é suplemento especial do volume 8 da $R B E$, de dezembro de 2005 .

Para caracterizar um periódico, de acordo com os critérios empregados pelas bases bibliográficas, em nosso caso o Scientific Electronic Library Online (SciELO) e a Literatura Latino-Americana e do Caribe em Ciências da Saúde (Lilacs), é imprescindível analisar os números regulares, nos quais se publicam 'artigos originais' apresentados pelo chamado 'fluxo contínuo' e que são apreciados pelo convencional processo de peer review, tal como apresentado nos itens anteriores. Publicamos um total de 25 números regulares, numerados de acordo com as regras de referência de periódicos. Desnecessário é mencionar novamente as dificuldades iniciais de regularidade de aparecimento dos números sucessivos. Entre esses 25 números, seis foram 'números temáticos'. Embora também estes tivessem sido apreciados pelo menos por um parecerista ad hoc, além dos editores especiais responsáveis por esses números, sofreram o que chamamos 'rito sumário', tradução livre do inglês fast track. Analisaremos apenas os artigos originais publicados nos demais 19 números regulares. Esperamos, assim, dar conta do perfil da $R B E$ no que tem de mais 'nobre': as características dos artigos publicados que foram analisados pelo processo normal de peer review.

Nesses 19 números foram publicados 158 artigos originais, com média de 8,3 trabalhos por número. Existe uma nítida progressão nessa média. No período inicial, os cinco primeiros números tiveram média de 6,2 trabalhos. Na transição, após ingresso na base Lilacs, os oito números seguintes tiveram média de 8,4 trabalhos, em vista da perspectiva de ingresso no SciELO. Após essa conquista, nos seis números seguintes cumpriu-se esse critério de inclusão da média de dez trabalhos por número. Os artigos publicados são em sua maioria produção coletiva, com média das médias de 3,3 autores por artigo. São raros os artigos de autor solitário, apenas 17 $(9,3 \%)$ no total. Também na média de autores, nos cinco primeiros números tivemos média menor $(2,7)$ de autores por artigo, estabilizando-se acima de três no período seguinte $(3,7)$, após ingresso no Lilacs, e conservandose $(3,2)$ após a entrada no SciELO. Apesar do esforço de ampla divulgação no exterior, especialmente na América Latina, o número de artigos publicados originados fora do Brasil foi pequeno nesse período, apenas 11 (7,0\%), a maioria de países vizinhos da América do Sul. Quanto à distribuição de origem nacional, por macrorregião, predominam obviamente aquelas onde se concentram os centros brasileiros de Saúde Coletiva: 101 no Sudeste $(63,9 \%), 22$ no Nordeste $(13,9 \%)$ e 19 no Sul $(12,0 \%)$; escassos quatro trabalhos do Centro-Oeste $(2,5 \%)$ e apenas um 
do Norte $(0,6 \%)$. As áreas temáticas e os desenhos metodológicos são os mais variados do amplo espectro por onde transita a epidemiologia brasileira. Deve ser mencionada, no entanto, a surpreendente escassez de artigos com metodologia qualitativa, predominando desenhos quantitativos (incluindo, obviamente, 'variáveis' qualitativas). Uma temática que se mostra freqüente na $R B E$ é associada a estudos de odontologia sanitária, tendo sido publicados nove artigos $(5,7 \%)$. Quanto à predominância feminina entre os autores, foi uma tendência que se consolidou com a própria $R B E$. No primeiro período, antes da entrada no Lilacs, tivemos 34 mulheres entre 83 autores $(41,0 \%)$. No segundo período, até o acesso ao SciELO, 158 em 246 (64,2\%), mantendo-se, a partir de então, 62,8\%. Conforme afirmamos no editorial reproduzido a seguir, "não expressamos juízo de valor". Essas questões estão presentes e discutidas em praticamente todos os editoriais. Transcrevemos um exemplo:

Neste número publicamos nove artigos, todos oriundos de diversas instituições situadas em todas as macro regiões [sic] do País, salvo a norte. Três trabalhos são do nordeste (Ceará, Paraíba e Piauí) e outros três do sudeste (dois de São Paulo, um de Minas Gerais). Um do sul (Santa Catarina) e outro do centro-oeste (Goiás). Além de um trabalho conceitual, de autoria de professora de São Paulo. Essa classificação está baseada na origem dos dados e da fonte geográfica das preocupações que motivaram os autores. A diversidade de origem institucional das equipes é ainda maior. O que já nos permite adiantar que, como tem sido usual, apenas dois dos trabalhos têm autorias individuais, um deles o já mencionado trabalho conceitual. A média de autores é de 3,6 , sendo que dos 32 autores $63 \%$ são mulheres. Não queremos expressar nenhum juízo de valor: cabe aos leitores interpretar. Não pode no entanto passar despercebido que a quase totalidade dos artigos tem base em dados originais obtidos diretamente pelos autores ou em dados buscados em fontes secundárias disponíveis. Como de hábito, desejamos a todos uma proveitosa leitura desses trabalhos. Desta vez, estendida aos que nos acessarem através da base SciELO. (Revista Brasileira de Epidemiologia, 8(1), mar.2005)

\section{Editoriais Particularmente Relevantes}

\section{Parecer de Comitê de Ética em Pesquisa (CEP) e Declaração de Conflito de Interesses}

Alguns trabalhos nos permitem retomar a discussão de dois temas para os quais temos chamado a atenção de autores, editores e pareceristas ad hoc: a submissão dos trabalhos a Comitês de Ética em Pesquisa (CEPs) e a declaração de potencial conflito de interesses. No primeiro, uma intervenção 
representada pela campanha de vacinação de idosos contra influenza é objeto de um estudo observacional. Emprega fontes de dados públicas e em casos como esse pode ser questionada a obrigatoriedade de submissão a um CEP. A questão é polêmica e pretendemos submetê-la a debate nos próximos números da RBE. No outro, o Editor Científico da RBE é diretamente interessado: o trabalho é resultado de um Projeto aprovado pelo Programa de Políticas Públicas da FAPESP em que é um dos coordenadores. A solução foi atribuir a condução do processo de julgamento, sigilosamente, a um dos Editores Adjuntos. Em outros casos, os autores devem estar atentos para identificar e explicitar os potenciais conflitos. Em estudos de avaliação de programas de saúde, por exemplo, é conveniente explicitar que relação os autores têm com as autoridades sanitárias responsáveis por sua execução. (Revista Brasileira de Epidemiologia, 7(2), jun.2004)

No número regular 7(2) de $R B E$ do mês do Congresso de Recife, publicamos um editorial especial dando conta dessa promoção regular da Comissão de Epidemiologia da Abrasco. Além da apreciação do editor ("Quatorze anos, de Carlos Gomes a Manuel Bandeira"), transcrevemos as apresentações de autoria dos presidentes dos seis congressos, desde 1990 em Campinas (terra do maestro) até 2004 em Recife (terra do poeta), passando por Belo Horizonte (1992), Salvador (1995), Rio de Janeiro (1998) e Curitiba (2002).

Assumindo o erro tático da primeira experiência de "Debate", inaugura-se novo procedimento: encomendar críticas. Anunciam-se novos temas:

Neste número retomamos uma iniciativa que já havia sido anunciada no primeiro ano de publicação da Revista Brasileira de Epidemiologia, a Seção de Debates. Introduzida, então, com um artigo de Maurício Barreto, "Por uma epidemiologia da saúde coletiva". Apesar da qualidade da contribuição, não teve o sucesso esperado quanto a promover um debate. Atribuímos a falta de resposta ao desafio implícito na matéria a três fatores principais. De um lado a pouca penetração de uma nova revista, em seu segundo número do primeiro ano de existência. Acrescido do erro tático de considerar que o ineditismo de algumas das idéias expressas pelo autor seria condição suficiente para atrair debatedores, que se apresentariam espontaneamente. Finalmente a falta de um mecanismo mais ágil de divulgação em meio virtual, possibilitando a participação de debatedores em qualquer parte do mundo. No Editorial do mesmo número, anunciávamos também o debate sobre um tema que, então como agora, se encontrava na ordem do dia, a questão do "duplo estândar" de ética da pesquisa em seres humanos, no primeiro mundo e na periferia. Também não prosperou.

Desta vez, estamos retomando um tema que de certa forma incide na mesma temática do artigo de Barreto. Trata-se da contribuição de Juan Gérvas e Mercedes Pérez Fernandez, da Equipe CESCA de Madrid, Espanha, que 
aborda "O fundamento científico da função de filtro do médico geral". Por fundamento científico os autores consideram a contribuição hegemônica da epidemiologia. Em particular, suas reflexões a respeito dos valores preditivos (positivo e negativo) das ações do médico geral e do especialista são dignas de uma reflexão cuidadosa sobre o sentido que essas duas "estatísticas" podem dar às formas que assumem os modelos de cuidados em saúde (uma resposta social organizada às doenças e agravos). Essa análise, de certa maneira, nos remete aos textos de Ricardo Bruno Mendes Gonçalves, especialmente sua tese de doutoramento na década de 80 do século passado. Refletindo sobre a dinâmica relação da clínica com a epidemiologia, Gonçalves considera que esta, entendida como tecnologia não material, é capaz de ordenar a prática da primeira: e a recíproca não é verdadeira. Num contexto brasileiro mais atual, é fundamental um mergulho nos rumos que está tomando o Sistema Único de Saúde (SUS), especialmente considerando iniciativas como: o Programa de Saúde da Família (PSF) e os seus agentes comunitários, médicos, enfermeiros, odontólogos, e outros; a ação da Agência Regulatória da Saúde Suplementar (ANS) em face de planos e seguros, de operadoras e prestadores; a ênfase que se dá cada vez mais às inovações em saúde e sua difusão na prática das ações individuais e coletivas. Para obviar os equívocos da iniciativa anterior, desta vez: primeiro, a RBE já não é tão pouco conhecida, após sete anos já estamos em diversas bases, especialmente no SciELO, o que nos dá oportunidade de induzirmos o debate, pelo menos no âmbito atingido por esta rede; segundo, já encomendamos as respostas de especialistas, que publicaremos no próximo número (setembro), mantendo o canal aberto a contribuições espontâneas. O debate será mediado pelos autores do artigo seminal, publicado neste número.

Outros temas polêmicos estão sendo preparados, também para o número de setembro. O primeiro é a retomada do debate da ética da pesquisa em seres humanos, ainda desta vez mediado por Dirceu Greco. Já havíamos publicado, em número de 2003, Editorial Especial deste autor abordando a álgida questão do tratamento a oferecer aos voluntários de estudos clínicos que venham a apresentar problemas de saúde. Em particular, os que vierem a se infectar com HIV nos estudos de vacinas preventivas, que é onde a questão tem sido mais discutida. Em recente "Consulta", realizada em março de 2005, em Blantyre (Malawi), na África, em conexão com o "Global Forum on Bioethics in Research" e o "Wellcome Trust", foi produzida matriz de ações que contextualiza a provisão de cuidados e tratamento aos voluntários dos estudos e introduz uma nova abordagem ("Research Governance") para dar conta do debate sobre as "best practices". Esta matriz encontra-se numa espécie de consulta pública e as revistas com "peer review”, como a nossa, estão chamadas a contribuir. O Professor Greco mediará o debate.

O segundo, que está por explodir, é a exigência de "Registro Obrigatório de Ensaios Clínicos". Esta exigência ganhou ênfase com o ultimato dado pelo Comitê de Editores das "principais” revistas da área de saúde aos laboratórios 
farmacêuticos: somente serão publicados, a partir de primeiro de julho deste ano, artigos científicos que tiverem sido previamente registrados em bancos públicos, tornados disponíveis a toda a sociedade. Sucessivas reuniões foram realizadas: em Nova Iorque, na Fundação Rockefeller, em outubro de 2004, na Cúpula de Ministros da Saúde, no México, em novembro do mesmo ano; em Genebra em abril de 2005 e, na seqüência, na Assembléia Mundial de Saúde, da OMS, em maio. A data fatal já foi abrandada, considerando que ensaios já em curso podem se adaptar até setembro. Diversas questões ainda estão pendentes, mas o mais importante, no contexto da América Latina, é saber que papel podemos representar: laboratórios produtores não pertencentes à "big pharma"; editores científicos da rede SciELO; e, especialmente, os pesquisadores desta parte do planeta. Para este debate, $o$ texto seminal pode ser o manifesto do "Comitê de Editores" que foi publicado em Editoriais de todas as publicações que se consideram pertencer a uma espécie de "big medical journals". Vamos providenciar para obter a autorização para transcrevê-lo no próximo número, mas desde já pode ser acessado "for free" nessas revistas. (Revista Brasileira de Epidemiologia, 8(2), jun.2005)

Editoriais especiais (temáticos), os "Debates" e as "Gavetas e Prateleiras" são nossa marca registrada.

Neste número incluímos Editorial Especial, contribuição de Sérgio Koifman, Editor Associado da RBE: Perdemos Richard Dollé um depoimento em que o homenageado se apresenta em suas feições humanas que tornavam ainda mais notável esse ícone da moderna Epidemiologia. Possivelmente a Revista Brasileira de Epidemiologia ainda venha a ser internacionalmente mencionada por ter publicado em seu segundo número, de 1998, um artigo original de Richard Doll, Epidemiology of chronic non-infectious disease: current status and future perspective. (Revista Brasileira de Epidemiologia, $8(3)$, set.2005)

Anuncia-se a ampliação do quadro de editores associados pela aceleração do fluxo contínuo:

Não é demais repetir que, aprovada para figurar na base SciELO, a Revista Brasileira de Epidemiologia passou a receber notável impulso no fluxo de trabalhos encaminhados. Mantida a regularidade exigida, o número de originais aumentou a ponto de exigir a ampliação do quadro de Editores Associados. No processo de peer review que empregamos cabe aos Associados o principal papel de conduzir a análise e elaborar o parecer final, raramente modificado pelo Editor Científico ou seus Adjuntos.

Finalmente, damos prosseguimento ao debate iniciado no número 8(2), de junho, com a publicação do texto seminal de Juan Gérvas sobre o fundamento epidemiológico do papel de filtro do sistema de saúde, exercido pelo médico geral. Teve prosseguimento no número seguinte, de setembro, com contribuição de autores espanhóis. Neste número apresentamos comentários 
de brasileiros e resposta dos autores do artigo original. (Revista Brasileira de Epidemiologia, 8(4), dez.2005)

Homenageamos Guilherme Rodrigues da Silva, ex-presidente da Abrasco e membro do Conselho Editorial da $R B E$. São várias manifestações de pesar por sua morte e a publicação de uma "Prateleira" de sua autoria. Inicia-se um novo tipo de debate sobre a gripe aviária, contendo contribuições curtas encomendadas a especialistas. Bárbara Starfield participa do debate sobre o 'papel de filtro' do generalista.

Morreu Guilherme Rodrigues da Silva, ex-Presidente da Abrasco e um dos mais influentes intelectuais da Saúde Coletiva brasileira e latino-americana. Com produção acadêmica reconhecida e valorizada, Guilherme foi liderança maior na construção da Reforma Sanitária Brasileira que teve seu apogeu na VIII Conferência Nacional de Saúde, em 1986, da qual foi o Relator. Sintonizado com a luta da sociedade por melhores condições de vida, exerceu diversos cargos relevantes, dos quais destacamos a Superintendência do Hospital das Clínicas da Faculdade de Medicina da USP, maior centro de atendimento hospitalar da América Latina. Guilherme associava uma vida intelectual intensa a uma expressiva atividade na formulação política e na ação concreta na área da saúde. Um verdadeiro dirigente. Este número da RBE aparece em luto fechado pela morte desse membro de seu Comitê Editorial, presença permanente em nossa memória.

Para homenagear Guilherme Rodrigues da Silva publicamos, além de diversas manifestações de pesar, um de seus textos expressivos no campo da Epidemiologia. Transcrição de conferência pronunciada em importante evento científico no início da década de oitenta do século XX, esse trabalho foi pouco divulgado e aparece em nossa seção de Gavetas e Prateleiras.

A ameaça à saúde global é cada vez mais presente, com a descrição da gripe em aves migratórias e sua difusão em aves domésticas confinadas. Atingindo pessoas na Ásia e, mais recentemente, na Europa e na África. Prosseguindo na linha editorial iniciada no último número da RBE, em dezembro de 2005, publicamos uma seção especial coordenada por Maria Rita Donalísio, com diversas opiniões de especialistas brasileiros sobre questões essenciais desse processo endemo-epidêmico. Esse debate continuará em números sucessivos. Neste, apresentamos: (1) Perspectivas da vigilância virológica no Brasil, Terezinha Maria Paiva, do Laboratório de Vírus Respiratórios, Instituto Adolfo Lutz, São Paulo; (2) Possíveis mutações do vírus H5N1 e sua adaptação na transmissão inter-humana, Rita Catarina Medeiros Souza, do Núcleo de Medicina Tropical, Universidade Federal do Pará e Laboratório de Vírus Respiratórios, Instituto Evandro Chagas; (3) Aspectos clínicos da influenza aviária, Luiz Jacintho da Silva, do Departamento de Clínica Médica, Faculdade de Ciências Médicas, Unicamp; (4) Eficácia da terapêutica antiviral em casos humanos, Dirceu Bartolomeu Greco, do 
Departamento de Clínica Médica, Faculdade de Medicina, Universidade Federal de Minas Gerais; (5) Perspectiva da produção da vacina no Brasil, Isaias Raw, do Instituto Butantan, São Paulo.

Na seção de Debates, prosseguimos na publicação de contribuições à polêmica sobre o "papel de filtro" do médico generalista no sistema de saúde. Neste número colhemos mais uma contribuição ao debate, da prestigiada intelectual norte-americana Bárbara Starfield. (Revista Brasileira de Epidemiologia, 9(1), mar.2006)

O futuro: o que nos reserva?

Somente a comunidade dos epidemiologistas brasileiros, na academia ou nos serviços de saúde, poderá responder com atos concretos. Em um projeto editorial isto quer dizer: manter a excelência dos atores e almejar que se tornem autores.

\section{REFERÊNCIAS BIBLIOGRÁFICAS}

CARVALHEIRO, J. R. Estratégias para divulgação da produção técnico-científica em epidemiologia. Cadernos de Saúde Pública, 6(3):319-329, 1990. Disponível em: <http://www.scielo.br>.

REVISTA BRASILEIRA DE EPIDEMIOLOGIA. Disponível em: <http:// www.scielo.br>. (Todos os editoriais referidos estão disponíveis on-line neste endereço eletrônico.) 


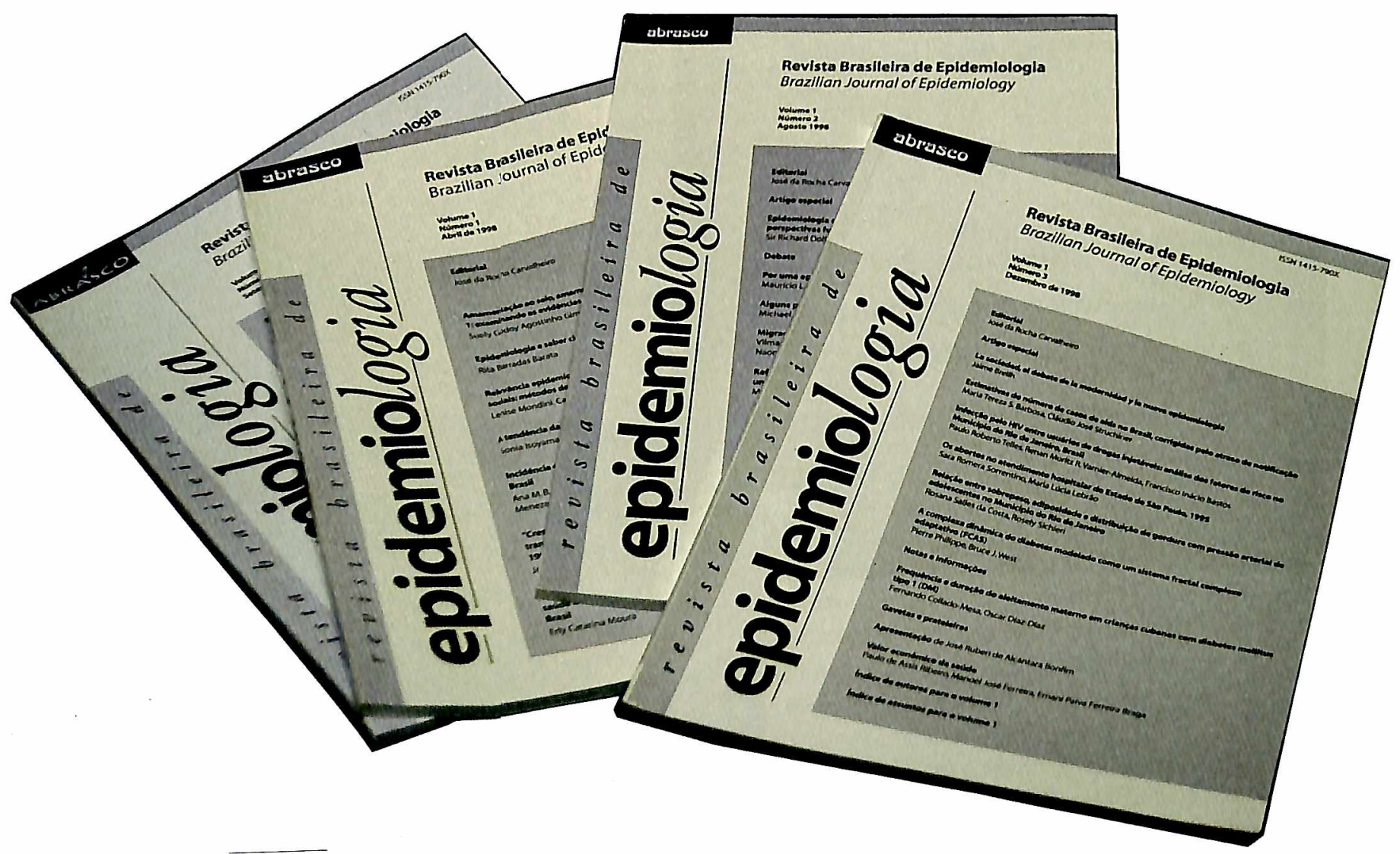

Imagem 16 


\section{EP I DEMIOLOGIA}

\section{CONGRESSO BRASILEIRO \\ II CONGRESSO IBERO-AMERICANO \\ I CONGRESSO LATINO-AMERICANO}

$1^{2}$ Mostra de Tecnologia em Epidemiologia - EPTTEC
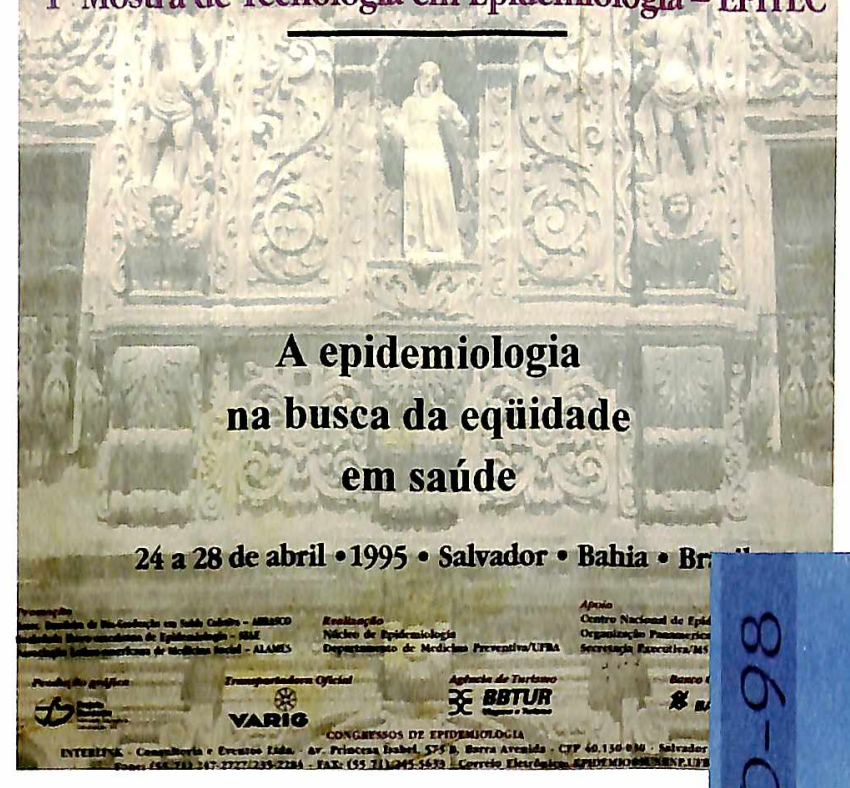

\section{$\infty$}

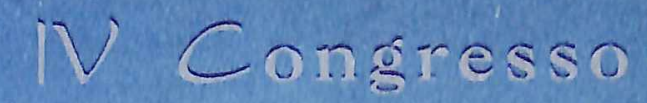
Brastientro de

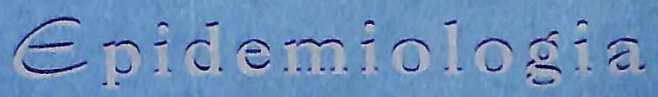

3 a 7 de agosto de 1998

Riocentro

Centro de Comvengines do Rio de Juneino

$\|$ Imagerm $\| 7$

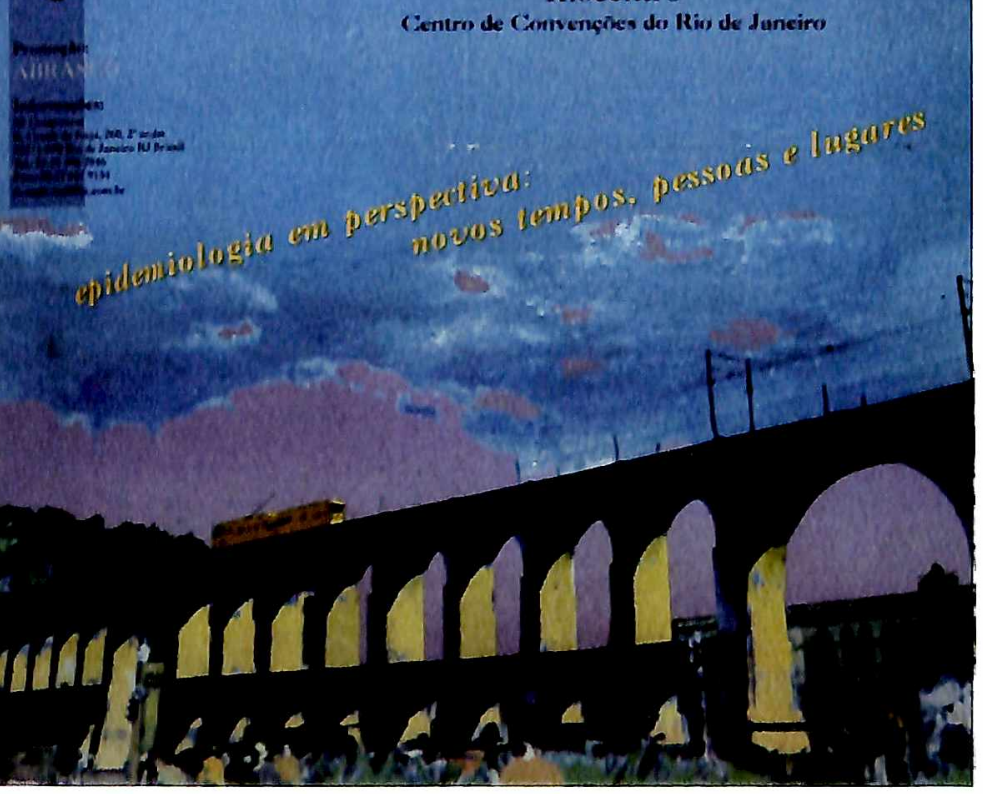

